\title{
Efficacy of a computerized cognitive training application on cognition and depressive symptomatology in a group of healthy older adults: a randomized controlled trial
}

\author{
José C. Millán-Calenti, Trinidad Lorenzo, Laura Núñez-Naveira, Ana Buján, José L. \\ Rodríguez-Villamil, Ana Maseda
}

\begin{abstract}
Objective. The purpose of this study was to evaluate the efficacy of a multimedia and interactive cognitive program on cognition and depressive symptomatology in healthy older adults.

Methods. Adults aged $\geq 65$ years were randomly assigned to two groups: the experimental group in which the participants received a computerized cognitive training application; and the control group in which the participants received no intervention during the protocol. Performance on the mini-mental state examination (MMSE) and the short-form of the geriatric depression scale (GDS-SF) were analysed using a three-way repeated-measure analysis of variance.

Results. To determine cognition after the training, the cognitive program was used and the results were assessed using the MMSE, indicating that the significant time effects within the groups reflected the score for cognitive assessment that was significantly better after the intervention in the experimental group. No significant differences were observed with regard to the depressive symptomatology or between the groups according to sex or educational level on the two dimensions previously established (cognition and depressive symptomatology).

Conclusion. The development of technological applications for intervention in older adults is increasing. Based on the established objective, we can conclude that the computerized intervention may constitute a good alternative to enhance the cognitive status in older people.
\end{abstract}

Keywords: Randomized controlled trial; Older people; Computerized cognitive training; cognition; Depression

\section{Introduction}

With ageing, there is an increased risk of experiencing a decline in cognitive abilities, which affects not only the functional dependence but also increases morbidity and mortality in the elderly population (Millán-Calenti et al., 2009). In recent years, non-pharmacological interventions for cognitive maintenance, such as stimulation or cognitive training programs, have proven to be an efficient tool as an isolated intervention and its association with several medications (Bergamaschi et al., 2013; Requena, Maestu, Campo, Fernández, \& Ortiz, 2006). Because cognitive decline is evident in the group of older people, there is increased interest in the use of cognitive training programs for the geriatric population. Information and communication technologies (ICT) may be used for cognitive training with older adults because the majority of the studies have proven that the elderly do not need to be technologically savvy to successfully complete or benefit from this training. Overall, the findings are comparable to or better than those reported in reviews of the more traditional, paper-and-pencil, cognitive training approaches, suggesting that computerized training is an effective and less labour-intensive alternative (Kueider, Parisi, Gross, \& Rebok, 2012). Nevertheless, several studies have shown negative results regarding such therapies, thus concluding that learning to use a computer and browsing the Internet does not benefit healthy, community-dwelling older adults with respect to many domains of cognitive functions (Slegers, van Boxtel, \& Jolles, 2009).

As a consequence of this important technological advance, several specialized memory aid software and commercial devices have been marketed (Caprani, Greaney, \& Porter, 2006; Maseda, Millán-Calenti, Lorenzo-López, \& Nuñez-Naveira, 2013); however, few of these types of software and devices have been scientifically tested and validated (Butti, Buzzelli, Fiori, \& Giaquinto, 1998; González-Abraldes et al., 2010; Shatil, Metzer, Horvitz, \& Miller, 2010; Tarraga et al., 2006). Although several reviews have indicated that computerized cognitive training is modestly effective in improving cognitive performance 
in healthy older adults and that the efficacy varies across cognitive domains largely determined by design choices, additional research is required to enhance the efficacy of the intervention (Lampit, Hallock, \& Valenzuela, 2014).

Computer-based cognitive stimulation appears to be a promising area of intervention and the limited data that are available support the hypothesis that computerized cognitive interventions can improve cognitive performance not only in older people with cognitive impairment but also in healthy older adults (Howren, Vander Weg, \& Wolinsky, 2014). Cognitive exercise training in the later stage of life may also have a beneficial effect independent of earlier life experiences (Valenzuela \& Sachdev, 2009). Other studies have demonstrated that cognitive stimulating activity might help to protect against cognitive decline in later life (La Rue, 2010; Maseda et al., 2013; Wilson, Scherr, Schneider, Tang, \& Bennett, 2007). This protective effect is in the order of approximately 40-50\%, even after simultaneous control for other risk factors, including educational level (Valenzuela, Breakspear, \& Sachdev, 2007). Nevertheless, Lojo-Seoane, Facal, Guàrdia-Olmos and Juncos-Rabadán (2014) showed that variables related to the educational level (e.g., years of education, occupational attainment, reading habits and crystallized intelligence) and lifestyle are the most important factors related to cognitive reserve and a general improvement in the execution of cognitive performance tasks.

Cognitive training studies in healthy older adults or the elderly with early-stage dementia have found that those people with better cognitive function at baseline have better post-treatment training effects (Lam, Lui, Luk, Chau, So, \& Poon, 2010; Valenzuela \& Sachdev, 2009). Several clinical trials have proposed that cognitive exercises might constitute an effective strategy for delaying the onset of cognitive impairment (Ball et al., 2002) or even improving the cognitive status in older adults with and without memory impairment (Maseda et al., 2013).

In addition to cognitive function, other areas of the person, such as the depressive symptomatology, could benefit from cognitive programs. The effectiveness of non-pharmacological intervention as an adjuvant therapy for this type of symptomatology in healthy older adults or elderly with early dementia has been under-explored thus far (Lam et al., 2010), although depression has proven to be a serious illness in older adults that often goes untreated because it is frequently misdiagnosed or confused with other symptomatology patterns (Kieffer \& Reese, 2002). Depression is a condition in which the patients fulfil at least five of the Diagnostic and Statistical Manual of Mental Disorder, Fifth Edition (DSM-5) (American Psychiatric Association, 2013) criteria for major depressive disorder (MDD) nearly every day during the same 2-week period. Several studies have demonstrated that depression was significantly reduced after cognitive training (Kim, Kim, \& Hong, 2010), even if it was a computerized cognitive training application (González-Palau et al., 2014), in healthy older adults and people with early Alzheimer's disease (Calvo, Rodríguez Pérez, Contador, Rubio Santorum, \& Ramos Campos, 2011; Lee, Yip, Yu, \& Man, 2013; Wolinsky et al., 2009).

Considering all of the above information, the objective of this work was to assess the effects of using a computerized cognitive training application on cognition and depressive symptomatology in a healthy population aged $\geq 65$ years. We examined and discussed how several socio-demographic factors, such as gender or educational level, would influence the efficacy of the training.

\section{Methods}

\subsection{Subjects}

A total of 160 older independent-living adults were voluntarily recruited from the local community centers in A Coruña area (northwest of Spain). A psychologist checked the eligibility of the participants according to the following inclusion criteria: submission of written informed consent, age $\geq 65$ years, and independent living in the community. The exclusion criteria were as follows: illiterate subjects, presence of any type of severe visual or hearing deficit, motor or not corrected deficit, cognitive impairment $(\leq 24$ points in the Spanish version of the mini mental state examination (MMSE) (Blesa et al., 2001; Folstein, Folstein, \& McHugh, 1975) or any psychiatric or neurological diagnosis.

A randomized controlled trial was conducted. A computer-based random number generator was used to divide the sample into 2 groups of 80 participants each. A total of 142 participants completed the study: 80 older adults in the experimental group and 62 in the control group due to withdrawal before the postintervention assessment. Examining the selectivity of attrition found that the participants who dropped out had no common characteristics. Furthermore, for the experimental group, the subjects had to perform the minimum established sessions (19 of 24 or completion of $80 \%$ of the training program). Progress was monitored automatically using an electronic data register. The participants' progress throughout the trial is shown in a Consolidated Standards of Reporting Trial (CONSORT) diagram (Fig. 1). 


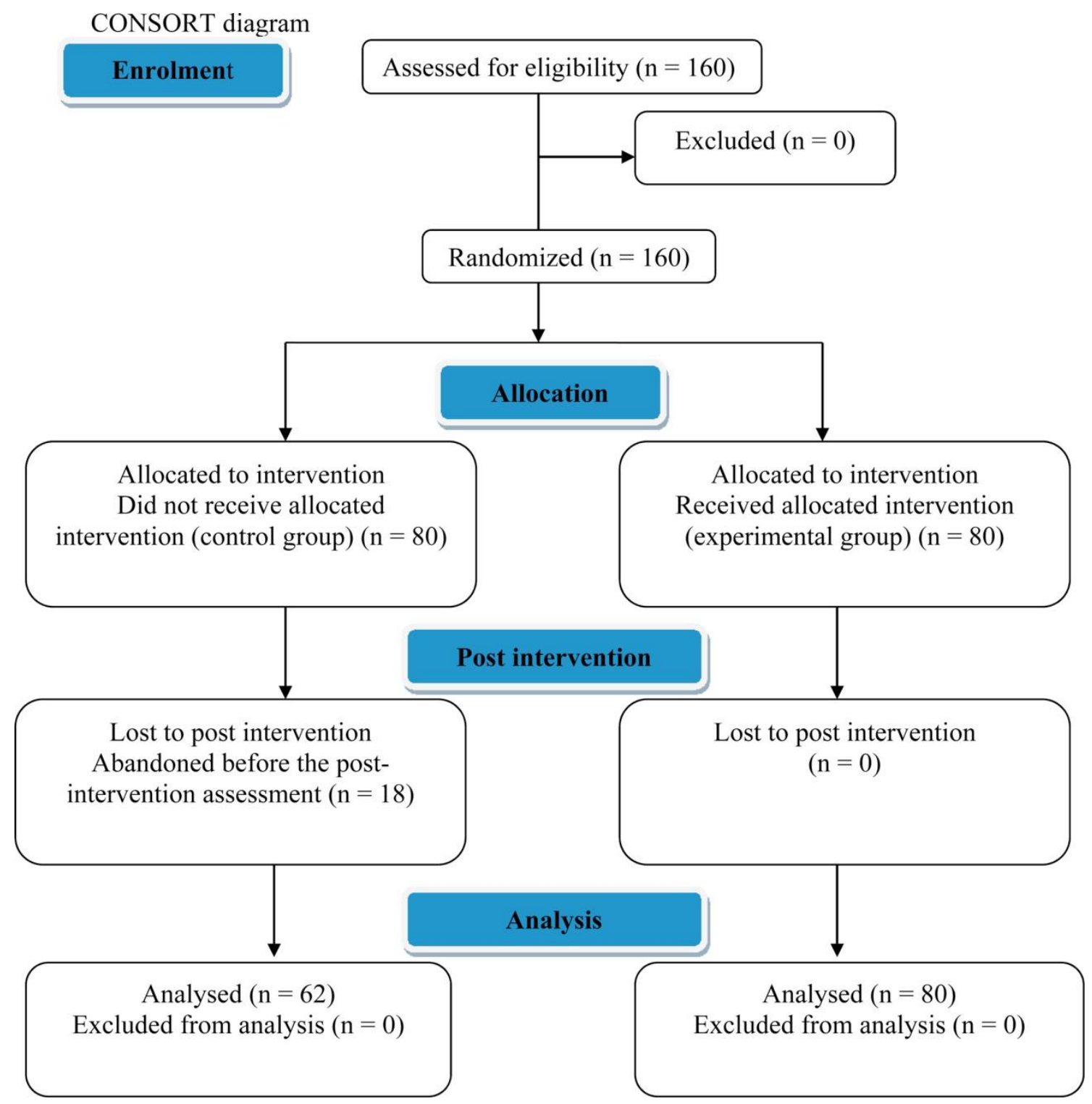

Fig. 1. CONSORT diagram.

All of the participants were assessed by trained professionals both before (pre intervention) and after the intervention (post intervention).

\subsection{Instruments and variables}

All of the participants were assessed using standardized tests that were validated in the Spanish language, in the following areas:

a) Cognition: The MMSE (Folstein et al., 1975) was used to assess the cognitive status and a validated Spanish version was administered (Blesa et al., 2001). This version provides an adjustment of scores for age and educational level. The adjusted scores ranged from 0 to 30, and the participants were considered to be cognitively impaired if they scored $\leq 24$.

b) Depressive symptomatology: Although there are many available instruments for assessing depression, the geriatric depression scale (GDS) (Yesavage et al., 1982) has been tested and extensively used in the older population (Wall, Lichtenberg, MacNeill, Walsh, \& Deshpande, 1999). A Short Form of the GDS (GDS-SF) was administered, consisting of 15 questions (Sheikh \& Yesavage, 1986); it was previously validated in the Spanish language (Martínez de la Iglesia et 
al., 2002); using a cut-off of $\geq 5$ points was recommended to consider the existence of probable clinical depression.

\subsection{Procedure}

The study protocol, which was approved by the Ethics Committee of the University of A Coruña, conformed to the principles embodied in the Declaration of Helsinki. Additionally, all of the participants were previously informed of the study and provided their consent to participate in the research. The intervention lasted for 12 weeks and consisted of 2-week sessions in which the users had to solve the activities included in the computerized cognitive training application, Telecognitio ${ }^{\circledR}$. This multimedia and interactive cognitive program has been described elsewhere (González-Abraldes et al., 2010 and Maseda et al., 2013). Each session lasted for approximately $20 \mathrm{~min}$, depending on the person's ability to solve the proposed activities.

\subsection{Statistical analysis}

The data analysis was conducted using the software package IBM SPSS Statistics v.21.0 (Armonk, NY: IBM Corp., USA). The quantitative variables were expressed as the mean \pm standard deviation (SD). The qualitative variables were expressed as absolute values and percentages. The normality of the data was tested using the Kolmogorov-Smirnov test. The differences in the distribution of the baseline characteristics between the control and the experimental groups were examined using chi-squared tests for the categorical variables and $t$-test for the continuous variables. Two three-way mixed analyses of variance (ANOVAs) were performed to assess the effects of treatment, sex or educational level and time on the two dimensions previously established (cognition and depressive symptomatology). In both ANOVAs, the within-participants variable was the measure over time (pre and post intervention), and the first between-participants variable was the group (experimental and control). The second betweenparticipants variable was a socio-demographic variable: in one ANOVA was the gender, and in the other was the educational level. The level of significance was set at $p<0.05$ with two tails for all tests with a 95\% confidence interval (CI). Bonferroni's tests for post hoc comparisons and Levene's test were used to assess the homogeneity of variances. Pairwise comparisons were performed for statistically significant simple main effects using Bonferroni correction. The effect size (partial eta square, $\eta_{p}^{2} \eta p 2$ ) and observed power for comparisons were presented.

\section{Results}

\subsection{Socio-demographic data and baseline assessment scores}

Table 1 shows the socio-demographic characteristics of the sample. The mean age of the total sample was 74.34 years $(\mathrm{SD}=6.40$ ) (women, $74.6 \%$ ). Concerning the educational level, $51 \%$ of the participants had no formal education, $23.9 \%$ had primary education, $7.6 \%$ had secondary education and $17.6 \%$ had a college degree or higher. 
Table 1. Characteristics of the participants at baseline.

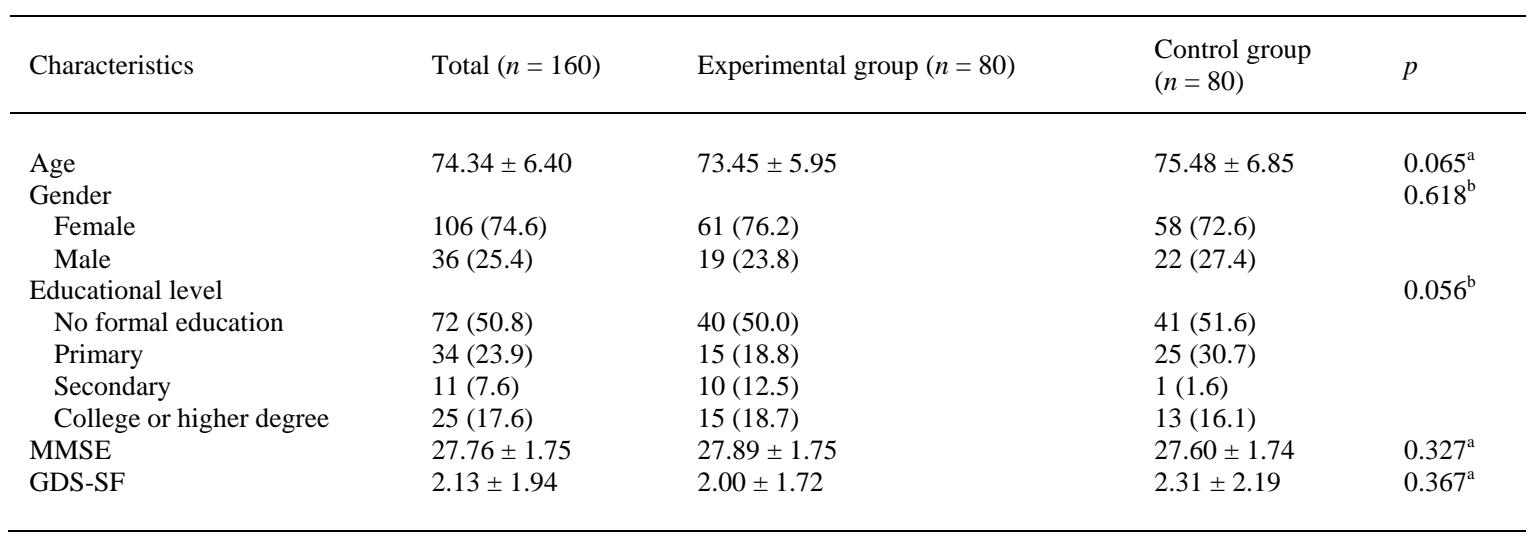

MMSE, mini-mental state examination; GDS-SF, global deterioration scale, short form.

a $t$-test.

${ }^{\mathrm{b}}$ Chi-squared test.

Table 1 shows the mean, SD and $p$ values for comparisons between the experimental and the control groups in the two assessed domains at baseline. According to the mean scores on the MMSE and GDS$\mathrm{SF}$, we observed that the participants were healthy older adults because they did not suffer cognitive impairment and depressive symptomatology. Moreover, no significant differences were observed between the groups in terms of socio-demographic characteristics and cognitive and depressive symptomatology, which assured the homogeneity of both samples.

\subsection{Intervention effect on cognition and depressive symptomatology}

The data were analysed using two three-way mixed ANOVAs with group of treatment and gender or educational level as between-participants factors and time as a within-participants factor.

First, with regard to cognition, the mixed ANOVA $($ group $\times$ gender $\times$ time $)$ did not show a significant three-way interaction $\left(F_{1,138}=0.022 ; p=0.883 ; \eta_{p \eta p 2}^{2}=0.000\right.$; observed power $\left.=0.052\right)$. Nevertheless, a statistically significant two-way interaction between the group of treatment and time for MMSE scores was observed $\left(F_{1,138}=29.744 ; p<0.001 ; \eta_{p \eta p}^{2}=0.177\right.$; observed power $\left.=1.000\right)$. There was a statistically significant simple main effect of group at post intervention $\left(F_{1,138}=20.732 ; p<0.001 ; \eta_{p}^{2} \eta p 2\right.$ $=0.131$; observed power $=0.995)$ but not at the pre intervention level. We observed an improvement in the mean cognition scores in the experimental group compared with the control group ( Table 2), with a mean difference of $1.483(95 \% \mathrm{CI}, 0.839-2.127 ; p<0.001)$. All other two-way interactions were not significant.

Table 2. Comparison of cognition and depressive symptomatology scores.

\begin{tabular}{llll}
\hline Group & & $\begin{array}{l}\text { Pre intervention } \\
\text { Mean } \pm \text { SD }(95 \% \text { CI })\end{array}$ & $\begin{array}{l}\text { Post intervention } \\
\text { Mean } \pm \text { SD (95\% CI) }\end{array}$ \\
\hline \multirow{2}{*}{ MMSE } & Experimental group $(n=80)$ & $27.89 \pm 1.75(27.50-28.28)$ & $28.74 \pm 1.50(28.40-29.07)$ \\
& Control group $(n=62)$ & $27.60 \pm 1.74(27.15-28.04)$ & $27.50 \pm 1.90(27.02-27.98)$ \\
GDS-SF & Experimental group $(n=80)$ & $2.00 \pm 1.72(1.62-2.38)$ & $1.36 \pm 1.61(1.00-1.72)$ \\
& Control group $(n=62)$ & $2.31 \pm 2.19(1.75-2.86)$ & $2.19 \pm 2.16(1.64-2.74)$ \\
\hline
\end{tabular}

CI, confidence interval 
With regard to the depressive symptomatology scores, no significant three-way interaction $($ group $\times$ gender $\times$ time $)$ was found $\left(F_{1,138}=0.861 ; p=0.355 ; \eta_{p}^{2} \eta \mathrm{p} 2=0.006 ;\right.$ observed power $\left.=0.152\right)$. The two-way interaction between the group of treatment and time was marginally significant $\left(F_{1,138}=3.832 ; p=0.052 ; \eta_{p \eta p 2}^{2}=0.027\right.$; observed power $\left.=0.494\right)$ because a decrease in the scores for the experimental group was observed ( Table 2). All other two-way interactions were not significant.

Second, when including the educational level variable in the three-way mixed ANOVA, no significant three-way interaction (time $\times$ educational level $\times$ group) was observed in any of the two dimensions (cognition: $F_{1,134}=1.477 ; \quad p=0.224 ; \quad \eta_{p \eta p 2}^{2}=0.032 ;$ observed power $=0.384 ;$ or depressive symptomatology: $F_{1,134}=0.439 ; p=0.726 ; \eta_{p}^{2} \eta p 2=0.010$; observed power $\left.=0.136\right)$. Again, the two-way interaction between the treatment group and time was significant for the MMSE $\left(F_{1,134}=9.199\right.$; $p=0.003 ; \eta_{p}^{2} \eta \mathrm{p} 2=0.064$; observed power $\left.=0.853\right)$ although not for $\operatorname{GDS}-\mathrm{SF}\left(F_{1,134}=1.699 ; p=1.195\right.$; $\eta_{p \eta p 2}^{2}=0.013$; observed power $\left.=0.253\right)$. As in the previous ANOVA, there was a statistically significant simple main effect of group at post intervention $\left(F_{1,134}=11.124 ; p=0.001 ; \eta_{p}^{2} \eta \mathrm{p} 2=0.077\right.$; observed power $=0.912$ ) but not at the pre-intervention level. We observed an improvement in the mean cognition scores in the experimental group compared with the control group ( Table 2), with a mean difference of 1.663 (95\% CI, 0.677-2.650; $p=0.001)$. All of the other two-way interactions were not significant.

In summary, the results for cognition assessed by the MMSE indicated the existence of significant time effects within the groups; the score for cognitive assessment was significantly better after the intervention in the experimental group (Table 2).

\section{Discussion}

The results of the present study indicated that there was a significant improvement in cognition in the experimental group. In the opposite direction, no differences were observed between the pre- and postintervention measurements of both characteristics in the control group. Additionally, the results suggested that regardless of gender and degree of educational level, there was not a statistically significant improvement in both characteristics in both groups after 12 weeks of computerized cognitive training.

The therapeutic efficacy of the cognitive program Telecognitio ${ }^{\circledR}$ was already proven on the cognitive status of older adults with and without memory impairment (Maseda et al., 2013), showing differences between pre- and post-intervention performance on the 7-Minute Screen. Our findings demonstrated improvement on the total score of the MMSE and therapeutic efficacy in the depressive symptomatology of healthy older people. Additionally, this work confirmed the results of previous studies demonstrating the beneficial effects of non-pharmacological computer-based training on the cognitive status of older adults (Cipriani, Bianchetti, \& Trabucchi, 2006; Gunther, Schafer, Holzner, \& Kemmler, 2003; Rozzini et al., 2007; Smith et al., 2009 and Talassi et al., 2007). However, other results showed no specific memory training effects in healthy older adults because the improvements observed in the experimental group did not exceed the improvement found in the active control condition (Martin, Clare, Altgassen, Cameron, \& Zehnder, 2011).

Research has also shown that cognitive training might help to protect against age-related cognitive decline (González-Abraldes et al., 2010, Maseda et al., 2013 and Wilson et al., 2007) and might reduce depressive symptomatology (Fernández Calvo, Rodríguez Pérez, Contador, Rubio Santorum, \& Ramos Campos, 2011; Lee et al., 2013 and Wolinsky et al., 2009). According to our results, this protective effect might not be closely related to several socio-demographic variables (Maseda et al., 2013), which is consistent with several systematic reviews on the subject that do not provide data for considering the differences by gender and educational level (Kueider et al., 2012).

Our study presented new data on this topic; however, additional research is required to explore the beneficial effects of these computerized programs in this specific population; according to the sociodemographic characteristics, the years of education demonstrated a strong association with the risk of dementia (McDowell, Xi, Lindsay, \& Tierney, 2007). It has been well recognized that a high educational level can be a neuroprotective factor against the negative aspects of neural ageing (Stern, 2002), thus leading to high pre-intervention scores in the MMSE, which could make it difficult to note significant effects after the intervention. In fact, several studies have suggested that people with lower educational level and who suffer from cognitive impairment are those who might more specifically improve after this type of intervention. However, at least one major epidemiologic study found that the frequency of recent cognitive leisure activity had a stronger link to the risk of developing Alzheimer's disease than the educational level or a low baseline cognitive function (Wilson et al., 2007). We should therefore consider that lifestyles that combine cognitively stimulating activities with physical activities and rich social 
networks may provide the best odds of preserving cognitive function in old age (Karp et al., 2006; La Rue, 2010).

\subsection{Strengths and limitations}

According to the proven efficacy of other studied computerized cognitive training applications, we must emphasize that Telecognitio ${ }^{\circledR}$, as a computerized cognitive training application, has shown consistent results similar to previous findings supporting the fact that interventions targeting multiple domains may be more effective than those treating each domain independently (Schneider \& Yvon, 2013). Additionally, our study was conducted in social associations and the intervention consisted of 2 weekly sessions. In general, group-based computerized cognitive training has been shown to be effective; however, home-based computerized cognitive training is not effective, and training more than three times a week is counterproductive (Lampit et al., 2014).

The current study presents a number of strengths that provide an added value to the results obtained. On the one hand, the study provides favorable evidence regarding the use of a method that is cheaper and non-invasive to prevent or delay the onset of cognitive impairment. On the other hand, adherence to the treatment is encouraged by an attractive format that is adapted to the cognitive ability of the participants, which surpasses the traditional techniques. Finally, it is important not to forget the potential of the ICT in the near future, given that the current population will age completely integrated with digital devices.

Furthermore, computer and Internet use can improve certain non-cognitive variables, such as depressive symptomatology. This social component of the new technologies is closely linked to the increase in overall life satisfaction (Karavidas, Lim, \& Katsikas, 2005) and the improvement in interaction using social networks (both on-line and face-to-face) (Heyn Billipp, 2001). Therefore, apart from training cognitive functions, many stimulation programs in social associations offer an innovative solution to satisfy the needs of the increasing old population and, hence, avoid isolation and promote social integration and people interconnectedness (Muncert et al., 2011). In fact, the only people who have withdrawn from the study belonged to the control group, with no cognitive computerized stimulation treatment, supporting the idea that the computerized training activities enhanced social participation in social associations. Nevertheless, more studies regarding the use of computerized cognitive training application in community centers are needed to validate the positive effect of this computerized training activity in the adherence to the program.

Despite the fact that computerized cognitive training programs seem to be an effective tool to be maintained as a community programme, it is necessary to state several limitations in this research. As suggested in other studies (Maseda et al., 2013), future studies should introduce non-cognitive outcome variables, such as well-being, quality of life or everyday functioning, as complementary measurements of the efficacy of computerized cognitive training applications. Cognitive status was assessed using MMSE, which is not the most sensitive tool to change in assessing cognitive status; however, it is a globally and frequently used screening test for assessing cognitive impairment within approximately 5-10 min (de Jager, Budge, \& Clarke, 2003; Helmes, 2013). As previously shown by Lin, O'Connor, Rossom, Perdue, \& Eckstrom, 2013, the MMSE remains the most thoroughly studied instrument; in their review, they found the most robust evidence for the MMSE; and depending on the cut-point, they found that sensitivity and specificity were approximately $91-92 \%$ and $56-96 \%$, respectively. The Spanish validation of the MMSE of Blesa et al. (2001) presented adequate data of internal reliability (Cronbach's alpha coefficient, 0.94), interrater reliability (intraclass correlation index, 0.96) and test-retest reliability (intraclass correlation coefficient, 0.87).

The MMSE had sufficient predictive power to screen for frailty in hospitalized older adults (Heim et al., 2015). The use of a neuropsychological battery would have been adequate; however, this type of assessment would require a longer interview with the participants, and given the nature of them (members of associations and non-institutionalized people), there could be decreased participation, especially in the post-intervention assessment. The GDS was found to have $92 \%$ sensitivity and $89 \%$ specificity when evaluated against the diagnostic criteria. The validity and reliability of the tool have been supported in both clinical practice and research. In a validation study comparing the long and short forms of the GDS for self-rating of symptoms of depression, both were successful in differentiating depressed from nondepressed adults with a high correlation $(r=0.84, p<0.001)$ ( Sheikh \& Yesavage, 1986). The Spanish validation of the GDS of Martínez de la Iglesia et al. (2002) showed an intraobserver reliability of 0.95 and an interobserver reliability of 0.65 , with an internal consistency of 0.99 . The sensibility reached $81.1 \%$ and the specificity reached $76.7 \%$, for a cut-point of $\geq 5$. Additionally, follow-up studies of the cognitive training efficacy would be required to evaluate the durability of the effect of the cognitive intervention and determine whether it lasts beyond the immediate post-intervention period or a continual 
cognitive training is required. Additionally, longer follow-up time intervals would be a favorable target in future studies.

\section{Conclusions}

The development of technological applications for intervention in older adults is increasing and has opened a wide range of new treatment possibilities. Based on the established objectives and the results obtained in this study, we can conclude that cognitive computerized intervention, such as Telecognitio ${ }^{\circledR}$ program, might constitute another alternative against ageing. This protective effect might be closely related to several socio-demographic variables (educational level). The computerized cognitive training programs might be a useful tool in clinical (e.g., hospitals and gerontological centres) and social (e.g., associations and local community centres) practice to improve or at least maintain the cognitive status in healthy older adults. Additional research is required to enhance the efficacy of the intervention.

\section{Conflict of interest}

The authors declare that they have no conflict interest.

\section{Ethical approval}

All of the procedures performed in the studies involving human participants were in accordance with the ethical standards of the institutional and national research committee and with the 1964 Declaration of Helsinki and its later amendments or comparable ethical standards.

\section{Informed consent}

Informed consent was obtained from all individual participants included in the study.

\section{Funding}

This research was supported by the project 0552_ENVEJECIMIENTO_ACTIVO_1_E (Operational Programme for Cross-border Cooperation Spain-Portugal, 2007-2013), co- funded by the European Regional Development Fund, European Union (ERDF, EU).

\section{Acknowledgements}

We thank the staff of the participating social associations in Galicia for providing us access to their older users, and we also appreciate the participants' collaboration in the cognitive training program.

\section{References}

American Psychiatric Association, 2013. American Psychiatric Association. Diagnostic and statistical manual of mental disorders. American Psychiatric Association (Ed.) (5th ed.)American Psychiatric Publishing, Washington, DC (2013) http://dx.doi.org/10.1176/appi.books.9780890425596.

Ball et al., 2002. K. Ball, D.B. Berch, K.F. Helmers, J.B. Jobe, M.D. Leveck, M. Marsiske, Advanced Cognitive Training for Independent Vital Elderly Study Group, et al.. Effects of cognitive training interventions with older adults: a randomized controlled trial. The Journal of the American Medical Association, 288 (18) (2002), pp. 2271-2281.

Bergamaschi et al., 2013. S. Bergamaschi, G. Arcara, A. Calza, D. Villani, V. Orgeta, S. Mondini. One-year repeated cycles of cognitive training (CT) for Alzheimer's disease. Aging Clinical and Experimental Research, 25 (4) (2013), pp. 421-426 http://dx.doi.org/10.1007/s40520-013-0065-2.

Blesa et al., 2001. R. Blesa, M. Pujol, M. Aguilar, P.I. Santacruz, G. Hernández, J.M. Sol, et al. Clinical validity of the 'mini-mental state' for Spanish speaking communities. Neuropsychologia, 39 (11) (2001), pp. 1150-1157 http://dx.doi.org/10.1016/S0028-3932(01)55-0.

Butti et al., 1998. G. Butti, S. Buzzelli, M. Fiori, S. Giaquinto. Observations on mentally impaired elderly patients treated with THINKable, a computerized cognitive remediation. Archives of Gerontology and Geriatrics, 26 (Suppl. 1) (1998), pp. 49-56 http://dx.doi.org/10.1016/S0167-4943(98)80009-5.

Caprani et al., 2006. N. Caprani, N. Greaney, N. Porter. A review of memory aid devices for an ageing population. PsychNology Journal, 4 (3) (2006), pp. 205-243.

Cipriani et al., 2006. G. Cipriani, A. Bianchetti, M. Trabucchi. Outcomes of a computer-based cognitive rehabilitation program on Alzheimer's disease patients compared with those on patients affected by mild cognitive impairment. Archives of Gerontology and Geriatrics, 43 (3) (2006), pp. 327-335 http://dx.doi.org/10.1016/j.archger.2005.12.003. 
de Jager et al., 2003. C.A. de Jager, M.M. Budge, R. Clarke. Utility of TICS-M for the assessment of cognitive function in older adults. International Journal of Geriatric Psychiatry, 18 (2003), pp. 318-324 http://dx.doi.org/10.1002/gps.830.

Fernández Calvo et al., 2011. B. Fernández Calvo, R. Rodríguez Pérez, I. Contador, A. Rubio Santorum, F. Ramos Campos. Eficacia del entrenamiento cognitivo basado en nuevas tecnologías en pacientes con demencia tipo Alzheimer. [Efficacy of cognitive training programs based on new software technologies in patients with Alzheimer-type dementia]. Psicothema, 23 (1) (2011), pp. 44-50.

Folstein et al., 1975. M.F. Folstein, S.E. Folstein, P.R. McHugh. Mini-mental state. A practical method for grading the cognitive state of patients for the clinician. Journal of Psychiatric Research, 12 (3) (1975), pp. 189-198 http://dx.doi.org/10.1016/0022-3956(75)90026-6.

González-Abraldes et al., 2010. I. González-Abraldes, J.C. Millán-Calenti, A. Balo-García, J. Tubío, T. Lorenzo, A. Maseda. Accesibility and usability of computer-based cognitive stimulation: Telecognitio. [Accesibilidad y usabilidad de las aplicaciones computarizadas de estimulación cognitiva: Telecognitio]. Revista Española de Geriatria y Gerontologia, 45 (1) (2010), pp. 26-29 http://dx.doi.org/10.1016/j.regg.2009.10.005.

González-Palau et al., 2014. F. González-Palau, M. Franco, P. Bamidis, R. Losada, E. Parra, S.G. Papageorgiou, et $a l$. The effects of a computer-based cognitive and physical training program in a healthy and mildly cognitive impaired aging sample. Aging \& Mental Health, 18 (7) (2014), pp. 838-846 http://dx.doi.org/10.1080/13607863.2014.899972.

Gunther et al., 2003. V.K. Gunther, P. Schafer, B.J. Holzner, G.W. Kemmler. Long-term improvements in cognitive performance through computer-assisted cognitive training: a pilot study in a residential home for older people. Aging and Mental Health, 7 (3) (2003), pp. 200-206 http://dx.doi.org/10.1080/1360786031000101175.

Heim et al., 2015. N. Heim, E.M. van Fenema, A.W. Weverling-Rijnsburger, J.P. Tuijl, P. Jue, A.M. Oleksik, et al. Optimal screening for increased risk for adverse outcomes in hospitalised older adults. Age Ageing, 44 (2) (2015), pp. 239-244 http://dx.doi.org/10.1093/ageing/afu187.

Helmes, 2013. E. Helmes. Cognitive screening of older adults: the utility of pentagon drawing. International of Psychogeriatrics, 25 (2013), pp. 413-419 http://dx.doi.org/10.1017/S1041610212001998 3).

Heyn Billipp, 2001. S. Heyn Billipp. The psychosocial impact of interactive computer use within a vulnerable elderly population: a report on a randomized prospective trial in a home health care setting. Public Health Nursing, 18 (2) (2001), pp. 138-145 http://dx.doi.org/10.1046/j.1525-1446.2001.00138.x.

Howren et al., 2014. M.B. Howren, M.W. Vander Weg, F.D. Wolinsky. Computerized cognitive training interventions to improve neuropsychological outcomes: evidence and future directions. Journal of Comparative Effectiveness Research, 3 (2) (2014), pp. 145-154 http://dx.doi.org/10.2217/cer.14.6.

Karavidas et al., 2005. M. Karavidas, N.K. Lim, S.L. Katsikas. The effects of computers on older adult users. Computers in Human Behavior, 21 (5) (2005), pp. 697-711 http://dx.doi.org/10.1016/j.chb.2004.03.012

Karp et al., 2006. A. Karp, S. Paillard-Borg, H.X. Wang, M. Silverstein, B. Winblad, L. Fratiglioni. Mental, physical and social components in leisure activities equally contribute to decrease dementia risk. Dementia and Geriatric Cognitive Disorders, 21 (2) (2006), pp. 65-73 http://dx.doi.org/10.1097/JGP.0b013e318190b691.

Kieffer and Reese, 2002. K.M. Kieffer, R.J. Reese. A reliability generalization study of the geriatric depression scale. Educational and Psychological Measurement, 62 (6) (2002), pp. 969-994 http://dx.doi.org/10.1177/0013164402238085.

Kim et al., 2010. Y.K. Kim, T.H. Kim, H.S. Hong. Effects of the cognitive training program on cognitive function, stress and depression of elderly patients in geriatric hospitals. Journal of Korean Biological Nursing Science, 12 (3) (2010), pp. 140-147.

Kueider et al., 2012. A.M. Kueider, J.M. Parisi, A.L. Gross, G.W. Rebok. Computerized cognitive training with older adults: a systematic review. PloS One, 7 (7) (2012), p. e40588 http://dx.doi.org/10.1371/journal.pone.0040588

La Rue, 2010. A. La Rue. Healthy brain aging: role of cognitive reserve, cognitive stimulation, and cognitive exercises. Clinics in Geriatric Medicine, 26 (1) (2010), pp. 99-111 http://dx.doi.org/10.1016/j.cger.2009.11.003.

Lam et al., 2010. L.C. Lam, V.W. Lui, D.N. Luk, R. Chau, C. So, V. Poon, et al. Effectiveness of an individualized functional training program on affective disturbances and functional skills in mild and moderate dementia-a randomized control trial. International Journal of Geriatric Psychiatry, 25 (2) (2010), pp. 133-141 http://dx.doi.org/10.1002/gps.2309.

Lampit et al., 2014. A. Lampit, H. Hallock, M. Valenzuela. Computerized cognitive training in cognitively healthy older adults: a systematic review and meta-analysis of effect modifiers. PLoS Medicine, 11 (11) (2014), p. e1001756 http://dx.doi.org/10.1371/journal.pmed.1001756.

Lee et al., 2013. G.Y. Lee, C.C. Yip, E.C. Yu, D.W. Man. Evaluation of a computer-assisted errorless learning-based memory training program for patients with early Alzheimer's disease in hong kong: a pilot study. Clinical Interventions in Aging, 8 (2013), pp. 623-633 http://dx.doi.org/10.2147/CIA.S45726.

Lin et al., 2013. J.S. Lin, E. O'Connor, R.C. Rossom, L.A. Perdue, E. Eckstrom. Screening for cognitive impairment in older adults: a systematic review for the U. S. Preventive Services Task Force. Annals of Internal Medicine, 159 (9) (2013), pp. 601-612 http://dx.doi.org/10.7326/0003-4819-159-9-201311050-00730.

Lojo-Seoane et al., 2014. C. Lojo-Seoane, D. Facal, J. Guàrdia-Olmos, O. Juncos-Rabadán. Structural model for estimating the influence of cognitive reserve on cognitive performance in adults with subjective memory complaints. Archives of Clinical Neuropsychology, 29 (3) (2014), pp. 245-255 http://dx.doi.org/10.1093/arclin/acu007.

Martin et al., 2011. M. Martin, L. Clare, A.M. Altgassen, M.H. Cameron, F. Zehnder. Cognition-based interventions for healthy older people and people with mild cognitive impairment. Cochrane Database of Systematic Reviews, 1 (2011), p. CD006220 http://dx.doi.org/10.1002/14651858.CD006220.pub2. 
Martínez de la Iglesia et al., 2002. J. Martínez de la Iglesia, M.C. Onís Vilces, R. Dueñas Herrero, C. Albert Colomer, C. Aguado Taberné, R. Luque-Luque. Versión española del cuestionario de Yesavage abreviado (GDS-SF) para el despistaje de depresión en mayores de 65 años: adaptación y validación. [The Spanish version of the Yesavage abbreviated questionnaire (GDS) to screen depressive dysfunctions in patients older than 65 years]. Medicina Familiar y Comunitaria, 12 (2002), pp. 620-630 http://dx.doi.org/10.4321/S1131-57682002001000003.

Maseda et al., 2013. A. Maseda, J.C. Millán-Calenti, L. Lorenzo-López, L. Nuñez-Naveira. Efficacy of a computerized cognitive training application for older adults with and without memory impairments. Aging Clinical and Experimental Research, 25 (4) (2013), pp. 411-419 http://dx.doi.org/10.1007/s40520-013-0070-5.

McDowell et al., 2007. I. McDowell, G. Xi, J. Lindsay, M. Tierney. Mapping the connections between education and dementia. Journal of Clinical and Experimental Neuropsychology, 29 (2) (2007), pp. 127-141 http://dx.doi.org/10.1080/13803390600582420.

Millán-Calenti et al., 2009. J.C. Millán-Calenti, J. Tubío, S. Pita-Fernández, I. González-Abraldes, T. Lorenzo, A. Maseda. Prevalence of cognitive impairment: effects of level of education, age, sex and associated factors. Dementia and Geriatric Cognitive Disorders, 28 (5) (2009), pp. 455-460 http://dx.doi.org/10.1159/000257086.

Muncert et al., 2011. E.S. Muncert, S.A. Bickford, B.L. Guzic, B.R. Demuth, A.R. Bapat, J.B. Roberts. Enhancing the quality of life and preserving independence for target needs populations through integration of assistive technology devices. Telemedicine Journal and e-Health, 17 (6) (2011), pp. 478-483 http://dx.doi.org/10.1089/tmj.2010.0206.

Requena et al., 2006. C. Requena, F. Maestu, P. Campo, A. Fernández, T. Ortiz. Effects of cholinergic drugs and cognitive training on dementia: 2-year follow-up. Dementia and Geriatric Cognitive Disorders, 22 (4) (2006), pp. 339-345 http://dx.doi.org/10.1159/000095600.

Rozzini et al., 2007. L. Rozzini, D. Costardi, B.V. Chilovi, S. Franzoni, M. Trabucchi, A. Padovani. Efficacy of cognitive rehabilitation in patients with mild cognitive impairment treated with cholinesterase inhibitors. International Journal of Geriatric Psychiatry, 22 (4) (2007), pp. 356-360 http://dx.doi.org/10.1002/gps.1681.

Schneider and Yvon, 2013. N. Schneider, C. Yvon. A review of multidomain interventions to support healthy cognitive aging. The Journal of Nutrition Health and Aging, 17 (3) (2013), pp. 252-257 http://dx.doi.org/10.1007/s12603-012-0402-8.

Shatil et al., 2010. E. Shatil, A. Metzer, O. Horvitz, A. Miller. Home-based personalized cognitive training in MS patients: a study of adherence and cognitive performance. NeuroRehabilitation, 26 (2) (2010), pp. 143-153 http://dx.doi.org/10.3233/NRE-2010-0546.

Sheikh and Yesavage, 1986. J.I. Sheikh, J.A. Yesavage. Geriatric depression scale (GDS-SF). Recent evidence and development of a shorter version. T.L. Brink (Ed.), Clinical gerontology: a guide to assessment and intervention, The Haworth Press, New York (1986), pp. 165-173.

Slegers et al., 2009. K. Slegers, M. van Boxtel, J. Jolles. Effects of computer training and internet usage on cognitive abilities in older adults: a randomized controlled study. Aging Clinical and Experimental Research, 21 (1) (2009), pp. $43-54$ http://dx.doi.org/10.1080/03601270600846733.

Smith et al., 2009. G.E. Smith, P. Housen, K. Yaffe, R. Ruff, R.F. Kennison, H.W. Mahncke, et al. A cognitive training program based on principles of brain plasticity: results from the improvement in memory with plasticitybased adaptive cognitive training (IMPACT) study. Journal of the American Geriatrics Society, 57 (4) (2009), pp 594-603 http://dx.doi.org/10.1111/j.1532-5415.2008.02167.x.

Stern, 2002. Y. Stern. What is cognitive reserve? Theory and research application of the reserve concept. Journal of the International Neuropsychological Society, 8 (3) (2002), pp. 448-460 doi:10.1017.S1355617701020240.

Talassi et al., 2007. E. Talassi, M. Guerreschi, M. Feriani, V. Fedi, A. Bianchetti, M. Trabucchi. Effectiveness of a cognitive rehabilitation program in mild dementia (MD) and mild cognitive impairment (MCI): a case control study. Archives of Gerontology and Geriatrics, 44 (Suppl. 1) (2007), pp. 391-399 http://dx.doi.org/10.1016/j.archger.2007.01.055.

Tarraga et al., 2006. L. Tarraga, M. Boada, G. Modinos, A. Espinosa, S. Diego, A. Morera, et al.. A randomised pilot study to assess the efficacy of an interactive, multimedia tool of cognitive stimulation in Alzheimer's disease. Journal of Neurology, Neurosurgery, and Psychiatry, 77 (10) (2006), pp. 1116-1121 http://dx.doi.org/10.1136/jnnp.2005.086074.

Valenzuela et al., 2007. M.J. Valenzuela, M. Breakspear, P. Sachdev. Complex mental activity and the aging brain: molecular, cellular and cortical network mechanisms. Brain Research Reviews, 56 (1) (2007), pp. 198-213 http://dx.doi.org/10.1016/j.brainresrev.2007.07.007.

Valenzuela and Sachdev, 2009. M. Valenzuela, P. Sachdev. Can cognitive exercise prevent the onset of dementia? Systematic review of randomized clinical trials with longitudinal follow-up. The American Journal of Geriatric Psychiatry, 17 (3) (2009), pp. 179-187 http://dx.doi.org/10.1097/JGP.0b013e3181953b57.

Wall et al., 1999. J.R. Wall, P.A. Lichtenberg, S.E. MacNeill, P. Walsh, S.A. Deshpande. Depression detection in geriatric rehabilitation: geriatric depression scale short form vs. long form. Clinical Gerontology, 20 (3) (1999), pp. 13-21 http://dx.doi.org/10.1300/J018v20n03_03.

Wilson et al., 2007. R.S. Wilson, P.A. Scherr, J.A. Schneider, Y. Tang, D.A. Bennett. Relation of cognitive activity to risk of developing Alzheimer disease. Neurology, 69 (20) (2007), pp. 1911-1920 http://dx.doi.org/10.1212/01.wnl.0000271087.67782.cb.

Wolinsky et al., 2009. F.D. Wolinsky, H.W. Mahncke, M.W. Weg, R. Martin, F.W. Unverzagt, K.K. Ball, et al. The ACTIVE cognitive training interventions and the onset of and recovery from suspected clinical depression. The Journals of Gerontology Series B, Psychological Sciences and Social Sciences, 64 (2009), pp. 577-585 http://dx.doi.org/10.1093/geronb/gbp061. 
Yesavage et al., 1982. J.A. Yesavage, T.L. Brink, T.L. Rose, O. Lum, V. Huang, M. Adey, et al. Development and validation of a geriatric depression screening scale: a preliminary report. Journal of Psychiatric Research, 17 (1) (1982), pp. 37-49 http://dx.doi.org/10.1016/0022-3956(82)90033-4. 